\title{
Reproductive Biology of the Brown Tree Snake, Boiga irregularis (Reptilia: Colubridae), during Colonization of Guam and Comparison with That in Their Native Range ${ }^{1}$
}

\author{
Fulie A. Savidge $e^{2,3}$,Fiona 7. Qualls ${ }^{2,4}$, and Gordon H. Rodda ${ }^{5}$
}

\begin{abstract}
Since their introduction to Guam shortly after World War II, brown tree snakes, Boiga irregularis (Merrem), have seriously impacted the biota and human population of the island. Understanding the biology of this exotic species will likely be important to the success of control programs. We compared the reproductive biology of 782 B. irregularis caught on Guam during the 1980s with results from published studies of native-range populations. Average and maximum sizes of mature snakes on Guam were larger than those from Australian populations. The majority of female brown tree snakes matured at snoutvent lengths (SVLs) of $910-1,025 \mathrm{~mm}$, and most males matured at SVLs of $940-1,030 \mathrm{~mm}$ on Guam. Based on growth rates from the early 1990s on Guam, sexual maturity is estimated to occur during a snake's third or fourth year. Only one female $(0.3 \%)$ in our data set had oviductal eggs. Clutch size was estimated at $4.3(\mathrm{SD}=2.2)$, based on large vitellogenic ovarian follicle ( $\geq 30 \mathrm{~mm}$ in length) and oviductal egg counts. Unlike their Australian counterparts, the Guam population reproduced year-round. Our data offer insights into the likely reproductive patterns of brown tree snakes should they infest other islands in the Pacific region.
\end{abstract}

Brown treE SNAKEs, Boiga irregularis (Merrem), were inadvertently introduced from Australasia to Guam around the end of World War II, and by the mid-1980s the snakes were abundant and distributed islandwide (Savidge 1987). To date, they have been responsible for the severe decline or extirpation of the island's native forest bird species (Savidge 1987), loss of two lizard species (Rodda and Fritts 1992), and a decline in numbers of the Mariana fruit bat, Pteropus $m$.

\footnotetext{
${ }^{1}$ Preparation of this work was supported by the U.S Department of the Interior's Office of Insular Affairs. Manuscript accepted 16 June 2006.

${ }^{2}$ Department of Fishery and Wildlife Biology, Colorado State University, Fort Collins, Colorado 80523.

${ }^{3}$ Corresponding author: jsavidge@cnr.colostate.edu.

${ }^{4}$ Current address: Jones County Junior College, 900 South Court Street, Ellisville, Mississippi 39437.

${ }^{5}$ U.S. Geological Survey, Fort Collins Science Center, 2150 Centre Avenue, Fort Collins, Colorado 80526.
}

Pacific Science (2007), vol. 61, no. 2:191-199

(C) 2007 by University of Hawai'i Press

All rights reserved mariannus (Wiles 1987, Wiles et al. 1995). In addition, they are a recognized public health threat (Fritts et al. 1990, 1994) and a substantial drain on the island's economy (Fritts et al. 1987, Fritts 2002). Accordingly, researchers and wildlife management agencies continue to develop tools aimed at controlling and eradicating brown tree snakes from Guam and stopping their spread to other islands. Consideration of biological factors when designing eradication and control programs allows for maximum effectiveness with limited resources.

Despite being the most intensively studied Boiga species, relatively little is known about the reproductive biology of the brown tree snake, either in its native range (Indonesia to Solomon Islands and the north and east rims of Australia) or on Guam. We present results from a study of the reproductive characteristics of the Guam population during the 1980s and include comparisons with data collected from native-range populations (in this case, Australia and Papua New Guinea). Combined with data from the 1980s on food habits and population characteristics of brown tree snakes 
on Guam (Savidge 1988, 1991), these data on reproductive biology provide a baseline for future comparisons and insight into the colonization process by supplying a snapshot of the reproductive characteristics of a recently established brown tree snake population.

\section{MATERIALS AND METHODS}

Between 1982 and 1987 one of the authors (J.A.S.) recorded morphological and reproductive data from 782 brown tree snakes (455 males, 327 females) that were collected from numerous sites on Guam. Approximately $65 \%$ of snakes in the study were livecaptured by hand or by trapping in nonurban locations. The remainder was obtained in urban areas, including a small number $(<10 \%)$ of roadkills. After collection, live snakes were killed by freezing. Sex, snout-vent length (SVL), total length, and mass of thawed snakes were recorded. In female snakes, ovarian follicles and oviductal eggs were grouped into size classes $(<5 \mathrm{~mm}, 5-19 \mathrm{~mm}, 20-29$ $\mathrm{mm}, \geq 30 \mathrm{~mm})$, the length of the largest ovarian follicle or oviductal egg measured, and the condition of oviducts recorded. We considered females sexually mature if oviductal eggs were present, ovarian follicles were $\geq 5 \mathrm{~mm}$ diameter, or oviducts were thickened (Shine 1987, 1991). Oviducts of 57 mature females were examined for presence of sperm by dissecting out the oviduct, gently washing it with water, and examining the fluid microscopically (Shine 1977). To assess activity of females with large follicles or oviductal eggs, the stomach was examined for evidence of recent foraging. The length of the right testis and the combined mass of both testes were recorded for all males. In addition, the condition of the vasa deferentia and the presence of spermatozoa were recorded for 147 individuals. The latter was determined by examining small macerated fragments of the vasa deferentia under a phase-contrast microscope (Shine 1977). Males were scored as mature if they showed fully developed convolutions (an indication of sperm presence) or spermatozoa were present.

We had no information on the maturation state of wild individuals of known age. How- ever, growth rates over 8.8 to 16.6 months were available for 36 wild snakes that initially ranged in SVL from approximately 580 to $1,250 \mathrm{~mm}$ (Rodda et al. 1999). We calculated an estimated mean age at maturity using our calculated mean sizes for sexual maturation and mean growth rates reported in Rodda et al. $(16.8 \mathrm{~mm} / \mathrm{month}$ and $13.1 \mathrm{~mm} / \mathrm{month}$ for males and females, respectively), assuming growth is constant from a hatching size of $375 \mathrm{~mm}$ SVL.

We used linear regression to analyze the relationship between SVL and testis mass. We plotted the residual scores from the regression (i.e., measures of testis mass corrected for the influence of body size) and used analysis of variance (ANOVA) to compare the mean residual testis mass among months. A square-root transformation normalized the testes mass data. Statistical significance was set at $P \leq .05$.

\section{RESULTS}

\section{Size and Age of Guam Brown Tree Snakes at Maturity}

Female B. irregularis matured over a large range of sizes on Guam (Table 1). The smallest female to show evidence of maturation measured $840 \mathrm{~mm}$ SVL. The largest female to show no evidence of maturation measured $1,110 \mathrm{~mm}$ SVL. Removal of outlying data points (the smallest $5 \%$ of mature females and largest $5 \%$ of immature females) indicates that $90 \%$ of females matured at SVLs between 910 and $1,025 \mathrm{~mm}$. Males matured over an even greater size range. The smallest mature male measured $805 \mathrm{~mm} \mathrm{SVL}$, and the largest immature male measured $1,135 \mathrm{~mm}$ SVL. However, $90 \%$ of males matured at SVLs between 940 and $1,030 \mathrm{~mm}$.

If sexual maturation occurs at the mean sizes estimated here and growth is constant, at the mean growth rates reported in Rodda et al. (1999), median age at maturity would be $3.1 \mathrm{yr}$ (males) and $3.7 \mathrm{yr}$ (females).

Females with Large Follicles or Oviductal Eggs

Fourteen females (4.3\%) had vitellogenic follicles $\geq 30 \mathrm{~mm}$ long, and an additional six fe- 
TABLE 1

Size and Mass at Maturity of B. irregularis Collected on Guam from 1982 to 1987 and from Australian Populations (Shine 1991)

\begin{tabular}{|c|c|c|c|c|}
\hline Population & Trait & & Males & Females \\
\hline \multirow[t]{9}{*}{ Guam } & \multirow[t]{3}{*}{ SVL (mm) } & Sample range $(n)$ & $375-2,400(455)$ & $350-1,650(327)$ \\
\hline & & Mature snake mean \pm SD $(n)$ & $1,308 \pm 298(191)$ & $1,078 \pm 138(124)$ \\
\hline & & Mature snake extremes & $805-2,400$ & $840-1,650$ \\
\hline & \multirow{3}{*}{$\begin{array}{l}\text { Total length } \\
(\mathrm{mm})\end{array}$} & Sample range $(n)$ & $480-2,910(453)$ & $453-1,990(326)$ \\
\hline & & Mature snake mean \pm SD $(n)$ & $1,652 \pm 362(191)$ & $1,366 \pm 165(123)$ \\
\hline & & Mature snake extremes & $1,030-2,910$ & $1,080-1,990$ \\
\hline & \multirow[t]{3}{*}{ Mass (g) } & Sample range $(n)$ & $7-2,300(453)$ & $7-1,800(327)$ \\
\hline & & Mature snake mean \pm SD $(n)$ & $523 \pm 538(191)$ & $230 \pm 228(124)$ \\
\hline & & Mature snake extremes & $60-\overline{2,300}$ & $67-\overline{1,800}$ \\
\hline \multirow{2}{*}{$\begin{array}{l}\text { New South Wales, } \\
\text { Australia }\end{array}$} & \multirow[t]{2}{*}{ SVL (mm) } & Mature snake mean $\pm \mathrm{SD}(n)$ & $1,015 \pm 249(42)$ & $976 \pm 157(21)$ \\
\hline & & Mature snake range & $624-1,630$ & $637-\overline{1}, 218$ \\
\hline \multirow{2}{*}{$\begin{array}{l}\text { Northern Territory, } \\
\text { Australia }\end{array}$} & \multirow[t]{2}{*}{ SVL (mm) } & Mature snake mean \pm SD $(n)$ & $1,035 \pm 163(24)$ & $974 \pm 118(22)$ \\
\hline & & Mature snake range & $850-1,535$ & $780-1,225$ \\
\hline \multirow[t]{2}{*}{ Queensland, Australia } & \multirow[t]{2}{*}{ SVL (mm) } & Mature snake mean \pm SD $(n)$ & $1,012 \pm 163(59)$ & $926 \pm 100(38)$ \\
\hline & & Mature snake range & $675-1,470$ & $725-1,185$ \\
\hline
\end{tabular}

Note: SVL, snout-vent length; SD, standard deviation; $n$, sample size.

males had follicles between 20 and $29 \mathrm{~mm}$ long. Only one female $(0.3 \%)$ had oviductal eggs. Of females with follicles $\geq 30 \mathrm{~mm}$ long, $79 \%$ had prey items in their stomachs. The one female with oviductal eggs had no prey items in its stomach. Locations, when known, for these females included the following: along road (3), in shrubs or trees (2), pothole in cliff line (1), on fence (1), in house (1), and under rock (1). Five were collected during night surveys of vegetation but exact locations were not recorded.

\section{Eggs and Clutch Size}

Of the snakes we examined, 14 had either large vitellogenic ovarian follicles $(\geq 30 \mathrm{~mm}$ long) or oviductal eggs that could serve as an estimate of clutch size (one additional female had a destroyed ovary). The mean clutch size of these 14 females was $4.3(\mathrm{SD}=2.2$, range 2-9).

\section{Seasonality of Reproduction of Brown Tree} Snakes

There is no evidence to suggest seasonal reproduction in brown tree snakes on Guam during the 1980s. Female snakes containing follicles $\geq 5 \mathrm{~mm}$ long or oviductal eggs were captured in every month (Figure 1). Mature male brown tree snakes exhibited a positive linear relationship between SVL and the square root of testis mass $\left(r^{2}=0.75 ; F=\right.$ 514.9; $\mathrm{df}=1,175 ; \quad P<.0001$ [Figure 2]). Mean residual testes mass did not differ among months ([Figure 3] $F=1.68$; df $=$ $11,164 ; P=.081)$. Only two males of 147 that were examined $(1.3 \%)$ lacked visible vas deferens convolutions.

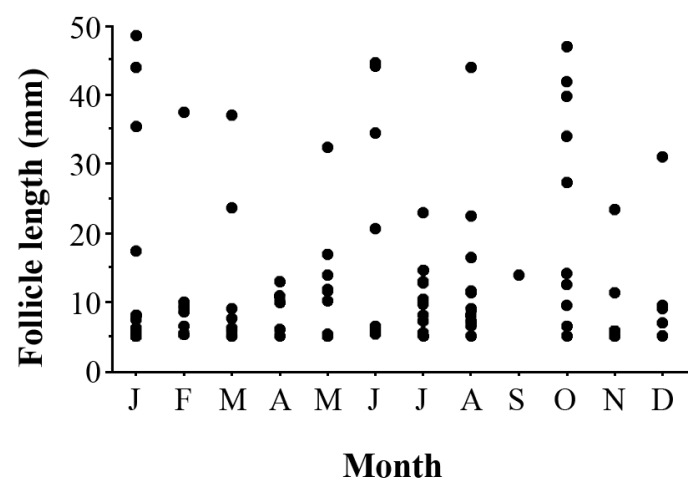

FIGURE 1. Monthly size distribution of ovarian follicles ( $\geq 5 \mathrm{~mm}$ long) in female Boiga irregularis. Females with enlarged follicles were captured in every month. 


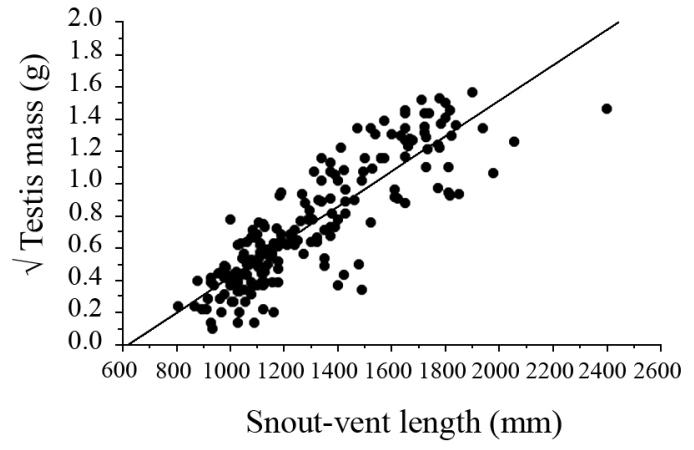

Figure 2. Relationship between snout-vent length and testis mass in mature male Boiga irregularis: square root of testis mass $=0.001$ SVL $-0.68, r^{2}=0.75$. Testis mass data were square-root transformed to ensure homogeneity of variances for analyses of monthly variation.

\section{Timing of Mating in Brown Tree Snakes}

Three mature females of 57 examined on Guam had observable sperm in their reproductive tract. These snakes were collected in April, June, and October. This sample of females containing sperm is small, and we cannot distinguish whether mating took place shortly before capture of the female, or if the sperm were stored from an earlier mating. However, two of the females had large follicles (42 and $45 \mathrm{~mm}$ long), suggesting that

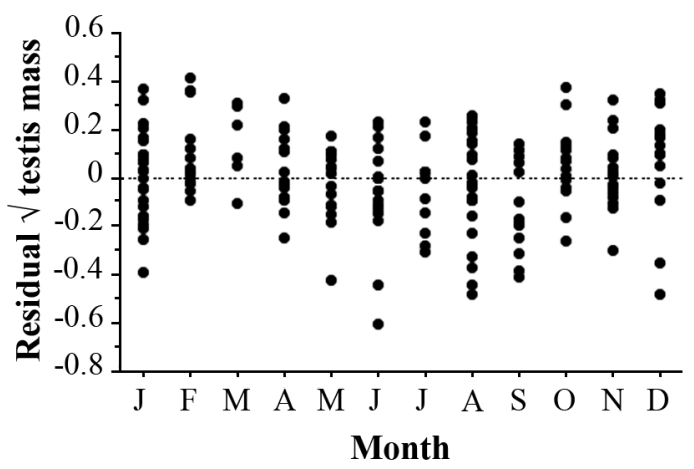

Figure 3. Annual distribution of testis mass (transformed to ensure homogeneity of variances in analyses and adjusted for systematic variation in snout-vent length) in mature male Boiga irregularis. Mean residual testes mass did not differ among months. mating may occur close to ovulation. A substantial proportion of mature male brown tree snakes on Guam appear physically capable of inseminating females (enlarged testes and vasa deferentia) at all times of year, so we cannot use our data from males to determine when mating occurred.

\section{DISCUSSION}

\section{Size and Age of Guam Brown Tree Snakes at Maturity}

Average and maximum sizes of mature snakes on Guam were larger than those from Australia (Table 1). Few equivalent data are available from non-Australian parts of the native range. Of special interest is Guam's presumed source population (Manus Island, Papua New Guinea, or the north coast of Papua New Guinea [Rodda et al. 1992]). If Guam snakes are indeed larger than those from the presumed source population, it is improbable that there has been selection for larger sizes on Guam, because brown tree snakes were introduced only about $30 \mathrm{yr}$ before our sampling (Savidge 1987, Rodda et al. 1992). More likely, their larger size resulted from a founder effect or exposure to environmental conditions that were more favorable to growth, survival, or both.

We estimated that sexual maturity occurred in a snake's third or fourth year. Note, however, that the growth data we used were collected during 1992 and 1993 and did not include hatchlings. Changes in Guam's biological environment in the years intervening between our study and the growth rate study or more complete sampling of juvenile growth rates may have resulted in changes in rate estimates (and therefore in ages at maturity).

\section{Females with Large Follicles or Oviductal Eggs}

Only one female in our sample had oviductal eggs. Gravid females are thought to be more secretive (Fitch 1960, 1987). The observation that most females with large ovarian follicles had prey in their digestive tract suggests that at least some females nearing ovulation are still actively foraging. 


\section{Eggs and Clutch Size}

Few data on egg dimensions and clutch size for brown tree snakes are available from Guam. Two hatched snake eggs (61 by 15 and 59 by $18 \mathrm{~mm}$ ) were found in 1984 on a ledge in what appeared to be a previously used Mariana Gray Swiftlet (Aerodramus bartschi) cave (Guam Division of Aquatic and Wildlife Resources, unpubl. data). Three clutches of three eggs (33-38 mm long by 13-15 mm wide [J.A.S., unpubl. data]), eight eggs (mean length and width of eggs $=43$ by $23 \mathrm{~mm}$ [McCoid 1994]), and 11 eggs (21$32 \mathrm{~mm}$ long by $17-24 \mathrm{~mm}$ wide [J.A.S., unpubl. data]), respectively, were obtained from females taken from the wild and into captivity.

Most gravid females in New Guinea had seven eggs (Parker 1982). Based on dissection of museum specimens and observations of captive snakes, Shine (1991) determined that clutch size in 21 Australian brown tree snakes ranged between 3 and 11 (mean $=5.5, \mathrm{SD}=$ 2.2). Mean size of eggs in two clutches from captive brown tree snakes in Australia was 52 by 15 and 56 by $17 \mathrm{~mm}$ (Shine 1991).

\section{Seasonality of Reproduction of Brown Tree Snakes}

There was no evidence of seasonal reproduction for male or female brown tree snakes on Guam. However, detection of subtle seasonal shifts in the proportion of females that were reproductive would require an even larger sample size, as only a very small percentage of snakes in our sample had oviductal eggs (i.e., only 1 female).

Our findings on Guam are in contrast to studies of Australian populations that found seasonal reproduction (Shine 1991, Whittier and Limpus 1996, Bull et al. 1997). All studies reported discrete reproductive seasons in Australia's tropical and subtropical study populations. However, males from Papua New Guinea had continuous testicular cycles (Bull et al. 1997). No data have been published for females from Papua New Guinea.

Guam's climate is typical of maritime tropical areas. There is little annual variation in temperature (range in monthly means, 25.7-26.9 ${ }^{\circ} \mathrm{C}$ [Figure 4]), so the thermal environment is unlikely to impose reproductive seasonality. However, rainfall varies throughout the year (Guam range in monthly means, $78-411 \mathrm{~mm}$ [Figure 4]), giving rise to distinct wet and dry seasons. Like Guam, the native range sites are maritime and experience mild temperatures throughout the year. However, all Australian sites studied have greater seasonality in temperature and rainfall than either Guam or Manus Island, the presumed source area for the Guam population (Figure 4). As illustrated by the climate diagrams, Brisbane experiences about 7 months of mild moisture deficit per year; Guam about 1 month; and Momote, Manus Island, has ample precipitation in all months.

Even males from populations with seasonal reproduction may be capable of inseminating females at all times of the year. After sperm are made in the testes, they travel to the vasa deferentia, where they may be stored for an extended period (Fitch 1982, Saint Girons 1982). Thus, male snakes with regressed testes may be capable of inseminating females using stored sperm. Sperm were present in the vasa deferentia of most snakes examined from subtropical southeastern Queensland (Bull et al. 1997). Furthermore, some snakes with sperm in their vasa deferentia were found year-round.

\section{Timing of Mating in Brown Tree Snakes}

Perhaps it is because brown tree snakes are cryptic and nocturnal that mating of brown tree snakes on Guam has never been recorded and has been documented in native-range populations only three times (Whittier and Limpus 1996). One pair of snakes from southeastern Queensland was observed mating in late summer (March), and two other matings were observed in spring (October and November) in northern and central Queensland (Whittier and Limpus 1996). The spring matings both occurred when reproductive females typically have vitellogenic follicles. Mating shortly before ovulation (during late vitellogenesis) is common in many snake species (Seigel and Ford 1987), 
Brisbane (38 m) 20.5 C $1151 \mathrm{~mm}$

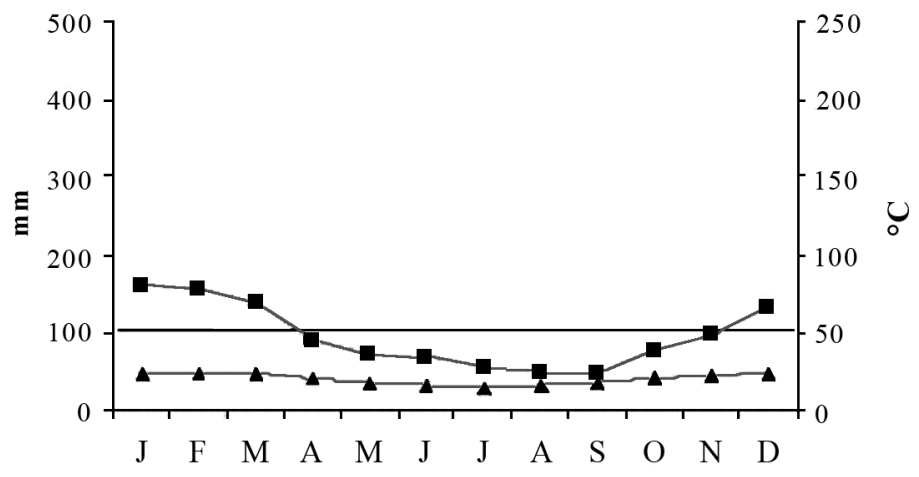

GUAM (110 m) $26.3 \mathrm{C} \quad 2509 \mathrm{~mm}$

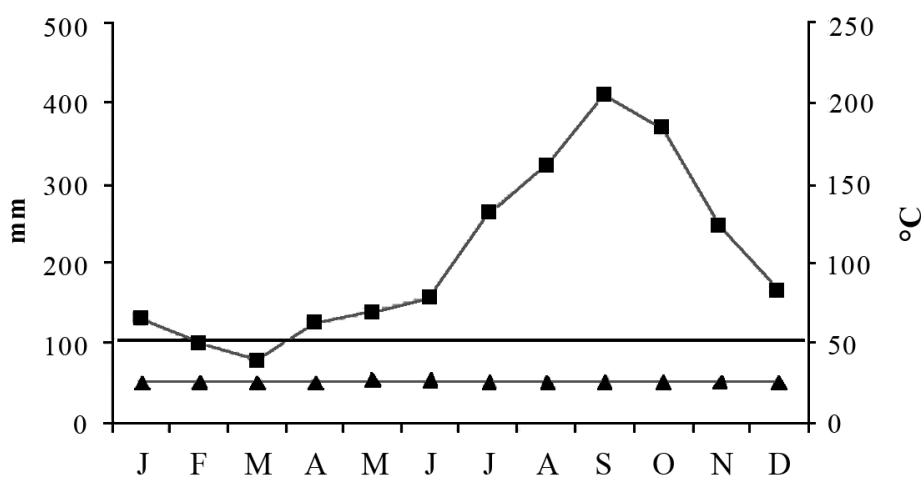

Momote (4 m) $27.3 \mathrm{C} \quad 3272 \mathrm{~mm}$

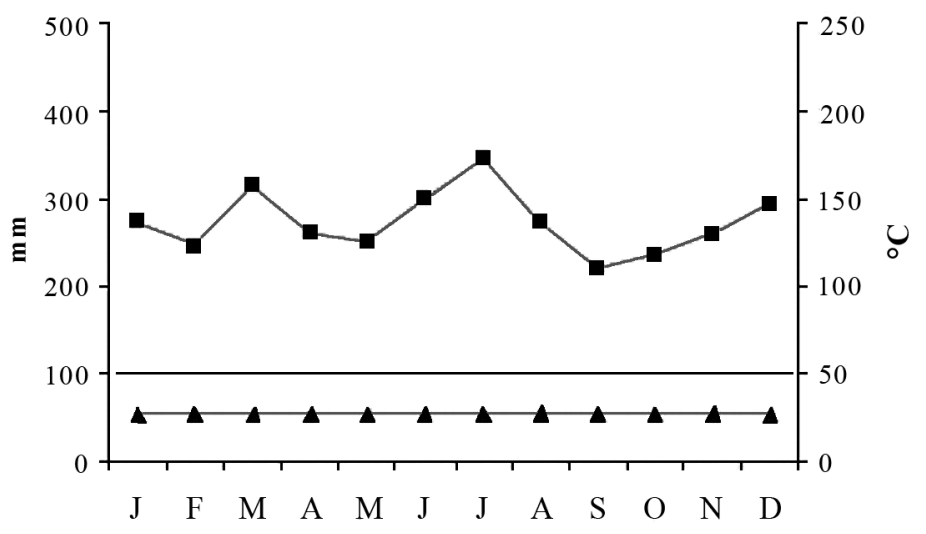

Figure 4. Climate diagrams for three sites relevant to Boiga irregularis reproductive studies: Brisbane (primary site of Australian reproductive studies), Guam (introduced population), and Momote, Manus Island (likely source of Guam population). During months when rainfall (square symbols, left axis) falls below the index line, plants are experiencing moisture stress. During months when rainfall falls below the temperature line (triangle symbols, right axis), plants are experiencing extreme moisture stress. The header values after each weather station name are elevation, mean temperature, and average monthly rainfall. Data from www.worldclimate.com, accessed 23 August 2005. 
and a piece of corroborating evidence supports the idea that Queensland brown tree snakes mate at that time. Examination of the oviducts of one spring-caught female containing large vitellogenic follicles found sperm in the vaginal segment of the snake's reproductive tract, close to the cloaca (Bull et al. 1997). The position and nature of the sperm (i.e., free in the lumen and not associated with the epithelium in a manner indicative of sperm storage) suggested that the female had been inseminated not long before she was preserved (Bull et al. 1997).

\section{Sperm Storage in Brown Tree Snakes}

The apparent aseasonality of reproductive cycles of both male and female brown tree snakes on Guam during the 1980s suggests that long-term sperm storage by either sex is not necessary for successful reproduction. However, we know that sperm storage by at least one sex is obligatory in some populations, because males in Queensland produce sperm at a different time of year than when females are ovulating (Whittier and Limpus 1996, Bull et al. 1997). In addition, the timing of the few published observations of mating in brown tree snakes suggests sperm storage in at least some populations (Whittier and Limpus 1996). Spring mating in Queensland requires that the snakes use sperm that were produced during winter and stored until spring. Bull et al. (1997) argued that male, but not female, brown tree snakes store sperm; sperm were found in the ductus deferentia of males from Queensland throughout the year $(n=40)$, and they found no seminal receptacles in female oviducts $(n=28)$. However, the late-summer mating suggests existence of an alternate reproductive pattern in Queensland brown tree snakes. At that time, testes are late recrudescent (Whittier and Limpus 1996, Bull et al. 1997) and females are postreproductive (Shine 1991, Whittier and Limpus 1996, cf. Bull et al. 1997). If published information on male and female reproductive cycles is accurate, for this latesummer mating to produce offspring, the female must be capable of storing sperm from March until at least September.
A female Boiga dendrophila (the purported sister species of $B$. irregularis) produced young after $2 \mathrm{yr}$ in isolation (J. D. Groves 1973). A female of another closely related species (Boiga multomaculata) is reported to have produced a clutch of fertile eggs more than 9 months after being placed in isolation (Kopstein 1938). Similarly, a female of another colubrid species, Leptodeira annulata (Haines 1940), produced viable young after being in isolation for $6 \mathrm{yr}$. These reports suggest that females of these species are capable of storing sperm for protracted periods. However, an alternative explanation is that some (or all) of these examples may have been cases of asexual reproduction, or parthenogenesis.

For many years the Brahminy blindsnake (Ramphotyphlops braminus) was thought to be the only parthenogenetic snake (Ota et al. 1991). Researchers recently have found asexual reproduction in snakes to be more widespread, with both obligate and facultative parthenogens (Dubach et al. 1997, Schuett et al. 1997). There are no confirmed cases of asexual reproduction in brown tree snakes. However, given the nature of data that have been collected to date, it is unlikely that parthenogenesis would have been identified if it were present. Two other colubrid species have been identified as facultative parthenogens (Thamnophis elegans vagrans and T. marcianus [Schuett et al. 1997]). Thus, it is possible that $B$. irregularis can reproduce asexually. If so, this would further reduce the minimum requirements for establishing extralimital populations of brown tree snakes from one previously mated female to one juvenile female, or even one egg.

\section{Frequency of Reproduction}

There are no direct data on the frequency of reproduction in brown tree snakes either on Guam or in native-range populations. Of 43 mature females collected from eastern Queensland during the putative reproductive period (April to December), only eight showed any sign of being reproductively active (vitellogenic follicles or oviductal eggs present [Whittier and Limpus 1996]). 
Moreover, females collected in subsequent months had no visible corpora lutea, implying that none was immediately postreproductive. Thus, we can conclude only that not all of the mature females in eastern Queensland reproduce every year or that the window of detection is short relative to the reproductive period.

Apparent differences in activity patterns of reproductive and nonreproductive females (i.e., gravid females possibly being more secretive) make it difficult to determine how often brown tree snakes reproduce. Two closely related snake species are known to produce multiple clutches in a year $(B$. blandingi [F. Groves 1973]; B. dendrophila [Luiselli et al. 1998]), suggesting that $B$. irregularis may also have this ability under suitable conditions.

\section{CONCLUSIONS}

There are several aspects of the biology of the introduced population on Guam for which we have little to no information (actual clutch sizes in the wild, timing of mating, frequency of reproduction). Where data exist, they often differ from those of the few published reports for Australian populations. For example, compared with their Australian counterparts, neither sex on Guam showed evidence of reproductive seasonality. The latter trait implies that sperm storage, though essential in parts of the native range, is unnecessary for successful reproduction on Guam. We know that many aspects of the Guam environment during the 1980s were very different from those experienced by the native-range populations and so were potentially a source of the observed differences. There are few available data on the reproductive biology of the presumed source population. Thus, we cannot rule out that snakes from the source also have large body sizes and aseasonal reproduction and that the differences between the Guam and Australian populations have a genetic basis.

\section{ACKNOWLEDGMENTS}

We thank G. Neubauer for her assistance in the field and the laboratory. T. Seibert, C. Tyrrell, T. Mathies, and two anonymous reviewers provided many useful comments on the manuscript. The Guam Division of Aquatic and Wildlife Resources supported data collection by J.A.S.

\section{Literature Cited}

Bull, K. H., R. T. Mason, and J. M. Whittier. 1997. Seasonal testicular development and sperm storage in tropical and subtropical populations of the brown tree snake (Boiga irregularis). Aust. J. Zool. 45:479-488.

Dubach, J., A. Sajewicz, and R. Pawley. 1997. Parthenogenesis in the Arafuran filesnake (Acrochordus arafurae). Herpetol. Nat. Hist. 5:11-18.

Fitch, H. S. 1960. Autecology of the copperhead. Occas. Pap. Mus. Nat. Hist. Univ. Kans. 13:85-288.

- 1982. Reproductive cycles in tropical reptiles. Occas. Pap. Mus. Nat. Hist. Univ. Kans. 96:1-53.

- 1987. Collecting and life-history techniques. Pages 143-164 in R. A. Seigel, J. T. Collins, and S. S. Novak, eds. Snakes: Ecology and evolutionary ecology. McMillan, New York.

Fritts, T. H. 2002. Economic costs of electrical system instability and power outages caused by snakes on the island of Guam. Int. Biodeterior. Biodegrad. 49:93-100.

Fritts, T. H., M. J. McCoid, and R. L. Haddock. 1990. Risks to infants from the bites of the brown tree snake (Boiga irregularis) on Guam. Am. J. Trop. Med. Hyg. 42:607-611.

- 1994. Symptoms and circumstances associated with bites by the brown tree snake (Colubridae: Boiga irregularis) on Guam. J. Herpetol. 28:27-33.

Fritts, T. H., N. J. Scott Jr., and J. A. Savidge. 1987. Activity of the arboreal brown tree snake (Boiga irregularis) on Guam as determined by electrical outages. Snake 19:5158.

Groves, F. 1973. Reproduction and venom in Blanding's tree snake. Int. Zoo Yearb. 13:106-108.

Groves, J. D. 1973. Delayed fertilization in the snake, Boiga dendrophila. Herpetologica 29:20-22. 
Haines, T. P. 1940. Delayed fertilization in Leptodeira annulata polysticta. Copeia 1940:116-118.

Kopstein, F. 1938. Ein beitrag zur Eierkunde und zur Fortpflanzung der Malaiischen Reptilien. Bull. Raffles Mus. 14:81-167.

Luiselli, L., G. C. Akani, and I. F. Barieenee. 1998. Observations on habitat, reproduction and feeding of Boiga blandingi (Colubridae) in south-eastern Nigeria. Amphib.-Reptilia 19:430-436.

McCoid, M. J. 1994. Boiga irregularis (brown tree snake): Reproduction. Herpetol. Rev. 25:69-70.

Ota, H., T. Hikida, M. Matsui, A. Mori, and A. H. Wynn. 1991. Morphological variation, karyotype and reproduction of the parthenogenetic blindsnake, Ramphotyphlops braminus, from the insular region of East Asia and Saipan. Amphib.-Reptilia 12:181-193.

Parker, F. 1982. The snakes of the Western Province. Wildl. Papua New Guinea 82:32-33.

Rodda, G. H., and T. H. Fritts. 1992. The impact of the introduction of the colubrid snake Boiga irregularis on Guam's lizards. J. Herpetol. 26:166-174.

Rodda, G. H., T. H. Fritts, and P. J. Conry. 1992. Origin and population growth of the brown tree snake, Boiga irregularis, on Guam. Pac. Sci. 46:46-57.

Rodda, G. H., T. H. Fritts, M. J. McCoid, and E. W. Campbell III. 1999. An overview of the biology of the brown treesnake (Boiga irregularis), a costly introduced pest on Pacific Islands. Pages 29-43 in G. H. Rodda, Y. Sawai, D. Chiszar, and H. Tanaka, eds. Problem snake management: The habu and the brown treesnake. Cornell University Press, Ithaca, New York.

Saint Girons, H. 1982. Reproductive cycles of male snakes and their relationship with climate and female reproductive cycles. Herpetologica 39:5-16.
Savidge, J. A. 1987. Extinction of an island forest avifauna by an introduced snake. Ecology 68:660-668.

- 1988. Food habits of Boiga irregularis, an introduced predator on Guam. J. Herpetol. 22:275-282.

- 1991. Population characteristics of the introduced brown tree snake (Boiga irregularis) on Guam. Biotropica 23:294300.

Schuett, G. W., P. J. Fernandez, W. F. Gergits, N. Casna, D. Chiszar, H. M. Smith, J. B. Mitton, S. P. Mackessy, R. A. Odum, and M. J. Demlong. 1997. Production of offspring in the absence of males: Evidence for facultative parthenogenesis in bisexual snakes. Herpetol. Nat. Hist. 5:1-10.

Seigel, R. A., and N. B. Ford. 1987. Reproductive ecology. Pages 210-252 in R. Seigel, J. Collins and S. Novak, eds. Snakes: Ecology and evolutionary ecology. McMillan, New York.

Shine, R. 1977. Reproduction in Australian elapid snakes I. Testicular cycles and mating seasons. Aust. J. Zool. 25:647-653.

. 1987. Food habits and reproductive biology of Australian snakes of the genus Hemiaspis (Elapidae). J. Herpetol. 21:7174.

. 1991. Strangers in a strange land: Ecology of the Australian colubrid snakes. Copeia 1991:120-131.

Whittier, J. M., and D. Limpus. 1996. Reproductive patterns of a biologically invasive species: The brown tree snake (Boiga irregularis) in eastern Australia. J. Zool. (Lond.) 238:591-597.

Wiles, G. J. 1987. Current research and future management of Marianas fruit bats (Chiroptera: Pteropodidae) on Guam. Aust. Mammal. 10:93-95.

Wiles, G. J., C. F. Aguon, G. W. Davis, and D. J. Grout. 1995. The status and distribution of endangered animals and plants in northern Guam. Micronesica 28:31-49. 
